\title{
Pattern of Upper Gastrointestinal Malignancies as Seen at Endoscopy in Ekiti State University Teaching Hospital, Ado-Ekiti, Nigeria
}

\author{
Akande Oladimeji Ajayi ${ }^{*}$, Ebenezer Adekunle Ajayi1, Olusoji Abidemi Solomon², \\ Emmanuel Abidemi Omonisi' ${ }^{3}$, Samuel Ayokunle Dada1 \\ ${ }^{1}$ Department of Medicine, College of Medicine, Ekiti State University, Ado-Ekiti, Nigeria \\ ${ }^{2}$ Department of Family Medicine, Ekiti State University Teaching Hospital, Ado-Ekiti, Nigeria \\ ${ }^{3}$ Department of Anatomic Pathology, College of Medicine, Ekiti State University, Ado-Ekiti, Nigeria \\ Email: *dejiajayi2@yahoo.co.uk
}

Received 12 May 2016; accepted 5 June 2016; published 8 June 2016

Copyright (C) 2016 by authors and OALib.

This work is licensed under the Creative Commons Attribution International License (CC BY). http://creativecommons.org/licenses/by/4.0/

(c) $\underset{\mathrm{BY}}{\mathrm{B}}$ Open Access

\section{Abstract}

Aims and Objective: Gastrointestinal malignancies are among the most lethal of all malignancies and are equally notorious for rapidly progressing to advanced stages even in the absence of serious symptoms, thus leading to delayed diagnoses and dismal prognoses. The aim of this study was to determine the prevalence, type, pattern and the histologic characteristics of upper gastrointestinal tumors seen in patients who underwent upper gastrointestinal endoscopy at the Ekiti State University Teaching Hospital, Ado-Ekiti, Nigeria. Materials and Methods: This was a three year cross-sectional study involving 78 patients with suspected upper gastrointestinal tumor referred for upper gastrointestinal endoscopy. The study was conducted from January 2011 to December 2013 at the Ekiti State University Teaching Hospital (EKSUTH), Ado-Ekiti, Nigeria. Relevant clinical information such as age, gender, clinical presentations, smoking history, alcohol use, spices, and consumption of opiates were obtained from the patients. Tissue biopsies were taken from the suspected lesions for histological confirmation and characterization. An ethical clearance for this study was obtained from the EKSUTH Ethical and Research committee and all the patients gave written consent for the study. SPSS version 15.0 (SPSS, Inc., Chicago, Illinois, USA) was applied for statistical analysis using the t-test for quantitative variables and $\chi^{2}$ test for qualitative variables. Differences were considered to be statistically significant if $P$ value was less than 0.05. Results: Seventy eight patients were enrolled into this study comprising 22 females and 56 males. The mean age of the population was $55.75 \pm 7.20$ years. The presenting symptoms were; abdominal mass in $30.8 \%$, abdominal pain in $29.5 \%$, weight loss in $20.5 \%$, dysphagia in $6.4 \%$, haematemesis in $5.1 \%$, melaena in $5.1 \%$ and anaemia in $2.6 \%$ of the patients. The risk factors identified in the study included; tobacco use or smoking in $25.6 \%$, alcohol in $19.2 \%$, spices in

${ }^{*}$ Corresponding author.

How to cite this paper: Ajayi, A.O., Ajayi, E.A., Solomon, O.A., Omonisi, E.A. and Dada, S.A. (2016) Pattern of Upper Gastrointestinal Malignancies as Seen at Endoscopy in Ekiti State University Teaching Hospital, Ado-Ekiti, Nigeria. Open Access Library Journal, 3: e2731. http://dx.doi.org/10.4236/oalib.1102731 
$14.1 \%$, opiates in $3.8 \%$ and combination of the above risk factors in $37.2 \% .67 .9 \%$ of the tumors were located in the stomach, $16.7 \%$ in the oesophagus and $15.4 \%$ in the first part of the duodenum. Of those located in the stomach, $62.3 \%$ were in the antrum while $37.7 \%$ were in the corpus. Of the oesophageal tumors, $61.5 \%$ were in the mid oesophagus, $30.8 \%$ were in the lower oesophagus and $7.8 \%$ in the upper oesophagus. Tissue histology showed $70.5 \%$ were adenocarcinoma, $26.9 \%$ were squamous cell carcinoma, $1.3 \%$ lymphoma and $1.3 \%$ malignant polyp. This was statistically significant $p=<0.05$. Conclusion: In view of the fact that upper GI tumors can rapidly progress to advanced stages in the absence of serious symptoms, gastroduodenoscopy is advocated in patients with signs and symptoms of dyspepsia to avoid delayed diagnosis and improve the disease outcome.

\section{Keywords}

Gastric cancer, Oesophageal Cancer, Upper GI Endoscopy

Subject Areas: Gastroenterology \& Hepatology

\section{Introduction}

The gastrointestinal (GI) tract along with its accessory glands is one of the most common systems of the human body affected by various cancers [1]. Gastric and gastro-esophageal adenocarcinomas are a major health burden globally. The incidence of upper gastrointestinal malignancies varies widely based on geographic location, race, and socioeconomic class [2]. Malignant tumors of the oesophagus are one of the commonest types of cancer. Globally, the incidence of oesophageal cancer is sixth and ninth among cancers in men and women, respectively, and is the fifth and ninth leading causes of cancer death [3]. Squamous cell cancer is the most common type of oesophageal carcinoma worldwide with more than $80 \%$ of these cancers occurring in developing countries [4].

Gastric cancer remains the world's third most common malignancy and the second leading cause of cancer mortality in the world [5]. A 2005 analysis of the global incidence and cancer related mortality revealed that 934,000 cases of gastric cancer occurred in 2002 and approximately 700,000 patients died annually from this problem [6]. In industrialized countries, mortality from gastric cancer has declined steadily over the years whereas gastric cancer remains a leading cause of death from cancer in the developing world. Geographical residence and dietary habits may play a part in the pathogenesis of gastric cancer. Social class and socioeconomic conditions of the inhabitants confer a significantly increased risk of developing gastric cancer. The pattern of upper GI cancer differs in different regions of the world depending upon the genetic, cultural, dietary and socioeconomic factors [7]. The aim of this study was to determine the prevalence, type, pattern and the histologic characteristics of upper gastrointestinal tumors seen in patients who underwent upper gastrointestinal endoscopy at the Ekiti State University Teaching Hospital, Ado-Ekiti, Nigeria.

\section{Materials and Methods}

This was a three year cross-sectional study involving 78 patients with suspected upper gastrointestinal tumor referred for upper gastrointestinal endoscopy. The study was conducted from January 2011 to December 2013 at the Ekiti State University Teaching Hospital (EKSUTH), Ado-Ekiti, Nigeria. Relevant clinical information such as age, gender, clinical presentations (like unexplained recent weight loss, abdominal pain or swelling, dysphagia, haematemesis or melaena and anaemia), smoking history, alcohol use, spices, and consumption of opiates were obtained from the patients.

Upper GI Endoscopy was performed in all the patients with Olympus EVIS GIF140 under 10\% xylocaine anaesthetic spray of the oropharynx and where necessary with intravenous midazolam $(5 \mathrm{mg})$ after vital signs were stabilized. The locations of the tumor were determined and recorded. Tissue biopsies were taken from the suspected lesions for histological confirmation and characterization. The tumors were classified by the predominant histological appearance into oesophageal squamous cell carcinoma/adenocarcinoma or gastric squamous cell carcinoma/adenocarcinoma, Lymphoma or Malignant polyp. Further categorizations into differentiated, moderately differentiated, undifferentiated or poorly differentiated carcinomas were made. 
An ethical clearance for this study was obtained from the EKSUTH Ethical and Research committee and all the patients gave written consent for the study. SPSS version 15.0 (SPSS, Inc., Chicago, Illinois, USA) was applied for statistical analysis using the t-test for quantitative variables and $\chi^{2}$ test for qualitative variables. Differences were considered to be statistically significant if $\mathrm{P}$ value was less than 0.05

\section{Results}

Seventy eight patients were enrolled into this study comprising 22 (28.2\%) females and 56 (71.8\%) males. The female: male ratio was 1:2.5. The mean age of the population was $55.75 \pm 7.20$ years (age ranged from $40-77$ ). Majority (76.9\%) of the patients were in the age group 41 - 60 years (Table 1). The presenting symptoms were; abdominal mass in $30.8 \%$ (24), abdominal pain in $29.5 \%$ (23), weight loss in $20.5 \%$ (16), dysphagia in $6.4 \%$ (5), heamatemesis in $5.1 \%$ (4), melena in $5.1 \%$ (4) and anaemia in $2.6 \%$ (2) of the patients (Table 2). The risk factors identified in the study included; tobacco use or smoking in $25.6 \%$, alcohol in $19.2 \%$, spices in $14.1 \%$, opiates in 3.8\% and combination of the above risk factors in 37.2\% (Table 3). Gender distribution of the risk factors was statistically significant $p=0.01$. Majority (67.9\%) of these tumors were located in the stomach, $16.7 \%$ in the oesophagus and $15.4 \%$ in the first part of the duodenum. Of those located in the stomach, $62.3 \%$ (33) were in the antrum while $37.7 \%$ (20) were in the corpus while none was found in the cardia. Of the oesophageal tumors, $61.5 \%$ (8) were in the mid oesophagus, $30.8 \%$ (4) were in the lower oesophagus and $7.8 \%$ (1) in the upper oesophagus. Tissue histology showed $70.5 \%$ (55) were adenocarcinoma ( $80 \%$ stomach, $18.2 \%$ duodenal and $1.8 \%$ oesophageal), $26.9 \%$ (21) were squamous (57.1\% oesophageal, $38.1 \%$ stomach and $4.8 \%$ duodenal), 1.3\% (1) lymphoma (duodenal) and 1.3\% (1) malignant polyp (stomach) (Table 4) This was statistically significant $p=<0.05$. As regards duration of symptoms before presentation and histological type, $60.3 \%$ (47) presented within six months (90.5\% of the squamous type and $50.1 \%$ of the adenocarcinoma type), $39.7 \%$ (31) presented after six months (9.5\% of the squamous type, $49.1 \%$ of the adenocarcinoma type while the patients with lymphoma and malignant polyp presented after six months. This was statistically significant $\mathrm{p}=0.005$.Fifty three (67.9\%) of the study population tested positive for $H$. pylori while the remaining twenty five (32.1\%) tested negative. Of the 53 that tested positive, 11 had squamous cell carcinoma, 40 had adenocarcinoma, 1 had lymphoma and another 1 had malignant polyp (Figure 1 and Figure 2). Five out of the thirteen that had oesophageal tumors were positive for $H$. pylori, 38 of the 53 that had stomach tumors were positive for $H$. pylori while 10 of the 12 that had duodenal tumors were positive for $H$. pylori (Table 5). This was found to be statistically significant $p=0.03$. Majority (60.3\%) of the patients presented within 6 months of the onset of symptoms while the remaining $39.7 \%$ presented after 6 months.

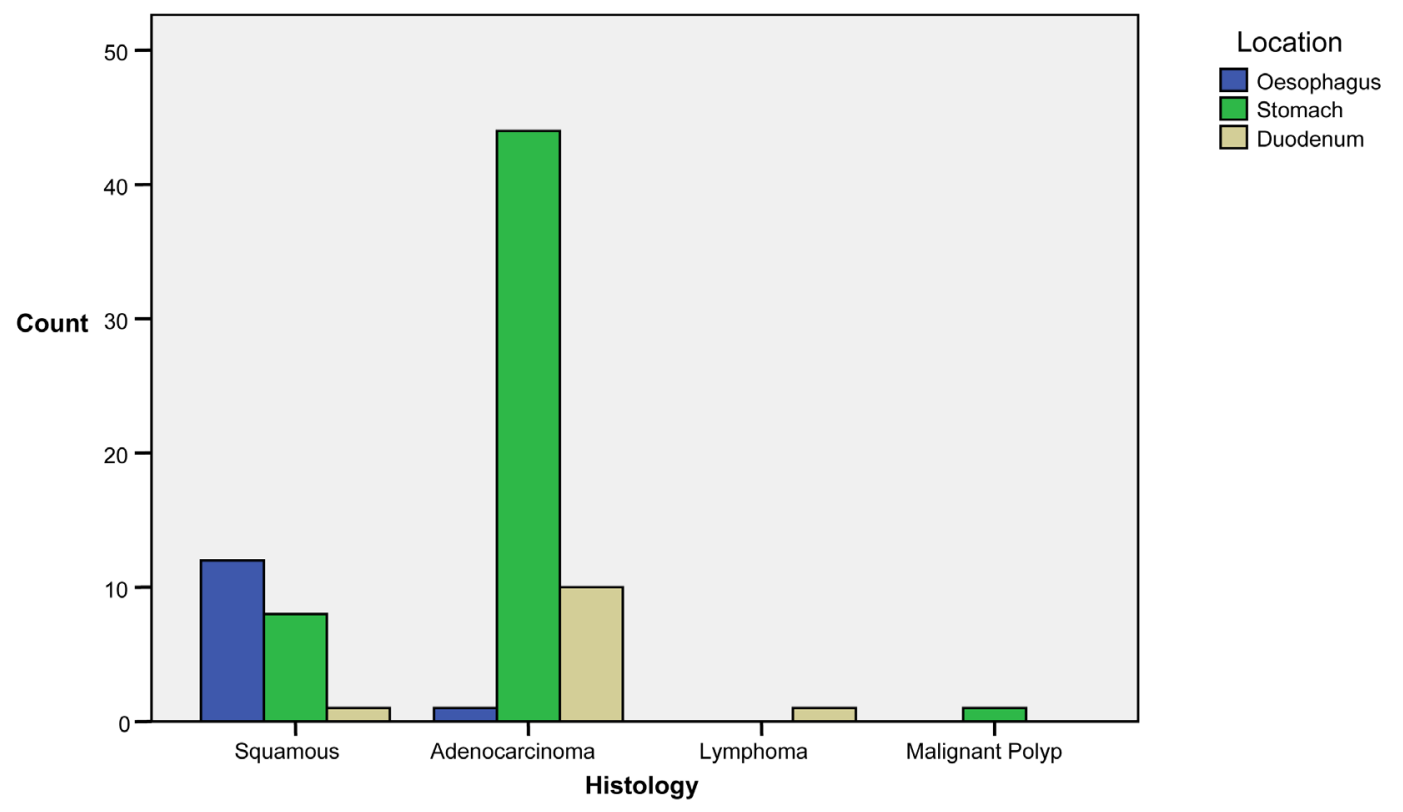

Figure 1. Showing histologic type and location. $p=<0.05$. 


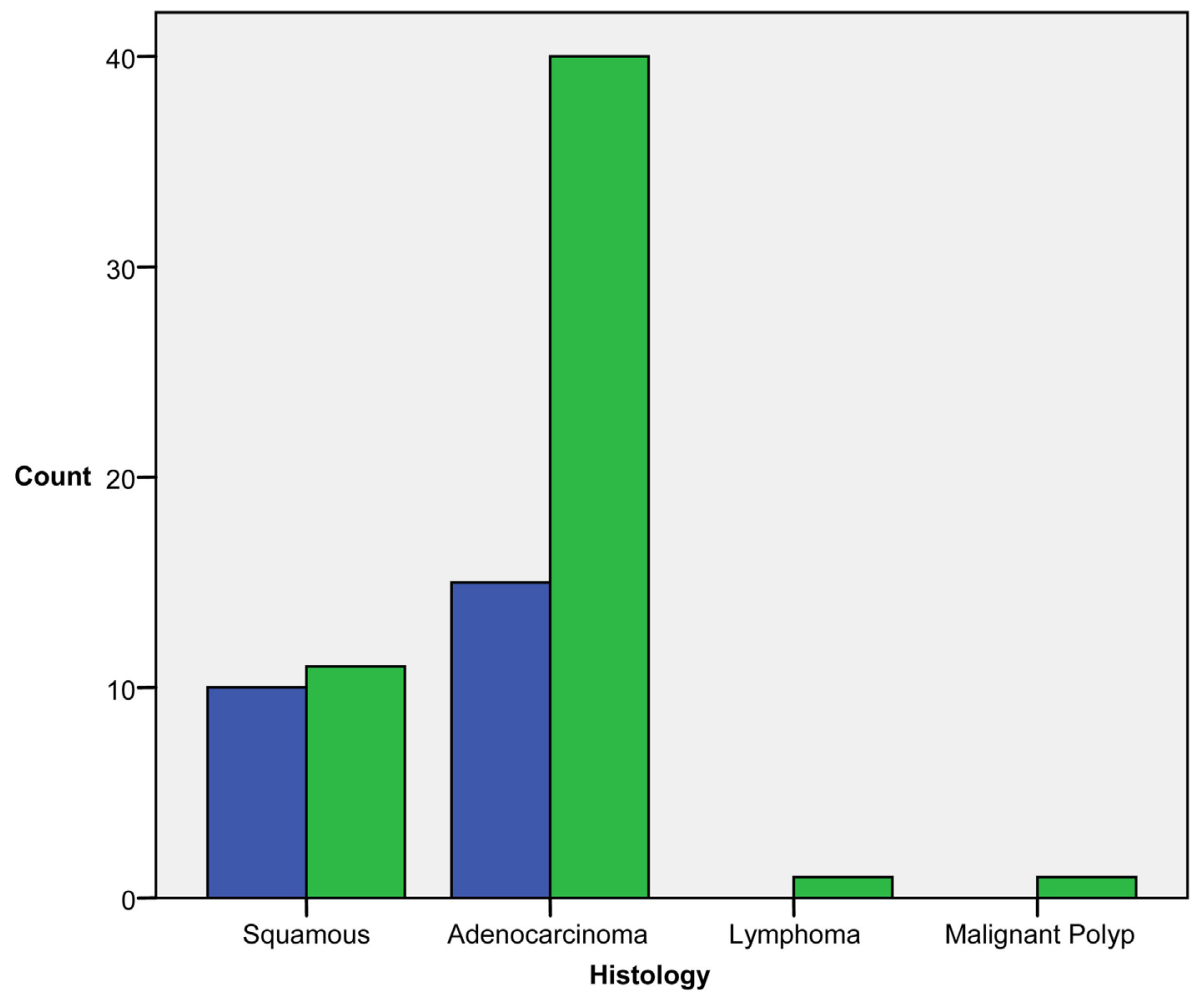

Hpyloristatus

$\square$ Negative

Positive

Figure 2. Showing the relationship between the histologic types and $H$. pylori status.

Table 1. Showing the age distribution of the population.

\begin{tabular}{ccc}
\hline Age group & Female & Male \\
\hline 40 Years and below & 1 & 0 \\
$41-50$ yrs & 3 & 29 \\
$51-60$ yrs & 9 & 6 \\
$61-70$ yrs & 7 & 2 \\
71 Yrs and above & 2 & 56 \\
Total & 22 & 56 \\
\hline
\end{tabular}

Table 2. Showing the presenting symptoms with gender distribution.

\begin{tabular}{cccc}
\hline Presenting symptoms & Female & Male & Total \\
\hline Abdominal mass & 9 & 15 & 24 \\
Abdominal pain & 5 & 18 & 23 \\
Haematemesis & 0 & 4 & 4 \\
Melaena & 0 & 4 & 4 \\
Anaemia & 1 & 11 & 16 \\
Weight loss & 5 & 3 & 5 \\
Dysphagia & 2 & 56 & 78
\end{tabular}


Table 3. Showing gender distribution of the risk factors.

\begin{tabular}{cccc}
\hline Risk factors & Female & Male & Total \\
\hline Alcohol & 3 & 12 & 15 \\
Tobacco/Smoking & 5 & 15 & 20 \\
Spices & 8 & 3 & 11 \\
Opium consumption & 1 & 2 & 3 \\
Combination of risk factors & 5 & 56 & 29 \\
Total & 22 & 58 \\
\hline
\end{tabular}

$p=0.01$.

Table 4. Showing histologic type and location.

\begin{tabular}{ccccc}
\hline Histology & Oesophagus & Stomach & Duodenum & Total \\
\hline Squamous & 12 & 8 & 1 & 10 \\
Adenocarcinoma & 1 & 44 & 1 & 55 \\
Lymphoma & 0 & 0 & 0 & 1 \\
Malignant Polyp & 0 & 1 & 12 & 78 \\
Total & 13 & 53 & 1 \\
\hline
\end{tabular}

$p=<0.05$.

Table 5. Showing relationship between $H$. pylori status and tumor location.

\begin{tabular}{cccc}
\hline Tumor location & H. pylori negative & H. pylori positive & Total \\
\hline Oesophagus & 8 & 5 & 13 \\
Stomach & 15 & 38 & 53 \\
Duodenum & 2 & 10 & 12 \\
Total & 25 & 53 & 78 \\
\hline
\end{tabular}

\section{Discussion}

Cancer incidence in general and GI cancer in particular varies widely in different parts of the world in different age groups. Gastrointestinal (GI) malignancies are among the most lethal of all malignancies and are equally notorious for rapidly progressing to advanced stages even in the absence of serious symptoms, thus leading to delayed diagnoses and dismal prognoses.GI malignancies constitute one of the major tumor burden to man. Studies from Africa showed lower incidence compared to other parts of the world [8]-[10].

In this study, upper GI malignancies occur more commonly in the male gender compared to the female counter part (2.5:1) and peaked between 40 - 60 year age group. This is in tandem with studies from Ibadan, Jos and some other parts of the world [2] [11]-[14]. The prevalence of oesophageal malignancies in this study was low (16.7\%) in keeping with many African based studies where oesophageal carcinoma ranges from $13.3 \%$ to $27.85 \%$ of all malignant gastrointestinal tumors [15]-[18]. Alcohol, smoking and spices are the three main risk factors identified in this study to be associated with the development of the malignancy of the upper gastrointestinal tract. This was similar to the risk factors found by Walker et al. [15].

In the US, the proportion of oesophageal adenocarcinoma (OAC) cases among all oesophageal cancer cases has increased from $14 \%$ to $51 \%$ from 1975 to 1998, and intestinal type OAC is now the predominant histological type [1]. Similar sharp increases in incidence of OAC have also been reported from Europe [19] [20]. In this series, Oesophageal squamous cell carcinoma (OSCA) was the predominant histologic type of oesophageal malignancy found in contrast to the changing trend in the US and Europe. Islami et al. [21] equally found OSCA as 
the predominant type of oesophageal cancer in the Golestan Province in Iran. In the study of Abdulkareem et al. [14], oesophageal cancers accounted for $2.5 \%$ with the majority having OSCA and more than half occurring in the 50 - 69 years age group. This prevalence of $2.5 \%$ was much lower than the $16.7 \%$ obtained in this study. This may be due in part to the fact that our study was endoscopy based and single centered while the other was multicentered and based on the review of embedded blocks and slides as well as pathological reports of malignant cancers of the whole GI tract.

In contrast to the studies of Durrani et al. [2] where oesophageal tumors were located in the upper third, middle third and lower third in 33\%, 22\%, and 34.6\% respectively, we found in this study oesophageal tumors located in upper third, middle third and lower third in 7.8\%, 61.5\% and 30.8\% respectively. Our finding was similar to the findings of Islami et al. [21] who found oesophageal tumors in upper, middle and lower thirds in $13 \%$, $54 \%$ and $33 \%$ respectively. Dysphagia was the major subjective complaint in cases of oesophageal carcinoma in keeping with findings in most studies.

Gastric malignancies are important cause of mortality from cancer and indeed the second most deadly malignant neoplasm worldwide. The prevalence of gastric malignancies in this study was quite high (67.9\%). This is similar to that obtained in some other studies across the world [22] [23]. The incidence of stomach cancer is said to be highest in Japan, China, South America and the Eastern Europe. The high prevalence obtained here was in sharp contrast to $13.3 \%$ recorded in Ibadan by Atoba et al. [11], 24.4\% in Jos by Obafunwa et al. [12] and 12\% recorded in Lagos by Abdulkareem et al. [14]. The difference may be due to the fact that our study was mainly that of the upper GI tract as seen on upper GI endoscopy and hence did not include other organs such as the liver, gall bladder, pancreas, etc as was the case in the above cited studies. Men were more than twice affected with stomach cancer in this study than females in keeping with the most reports from other studies [2] [14] [23]. Stomach malignancy can occur in any part of the stomach and this is said to have a bearing on the prognosis. Distal malignancies is generally said to have a five-year survival rate of between $20 \%-25 \%$ after resection while those patients with proximal malignancies has reduced survival rate which is reflective of a more aggressive and diffuse histologic disease. Of those located in the stomach, 62.3\% (33) were in the antrum, 37.7\% (20) were in the corpus while none was found in the cardia. Majority (80\%) were adenocarcinoma while the remaining $20 \%$ were squamous cell type. Intestinal cell type was the predominant cell type found among the patients with gastric cancer. The age incidence and histological characteristics recorded in this series are similar to reports in the literature [13]. In line with the findings in most studies, the most common presenting symptom in case of carcinoma of stomach was epigastric pain while dysphagia was the most common presenting symptom in oesophageal cancers.

Helicobacter pylori has been found to be strongly associated with the development of precancerous lesion of gastric carcinomas and despite high seroprevalence of between $80 \%$ - $85 \%$ in healthy individuals, detection rate of the organism inmalignant tissue is quite low [13]. H. pylori positivity in this study for those with gastric cancer was $71.7 \%$ and $38.5 \%$ for oesophageal cancer. This was significant statistically $(p=0.03)$. This is not surprising considering the high prevalence of $H$. pylori infection in Nigeria. Majority (60.3\%) of the patients in this study presented at the hospital within 6 months of the onset of symptoms while the remaining $30.7 \%$ presented after 6 months. All the patients were seen at the advanced stage of the disease thus confirming the fact that these tumors are notorious for rapidly progressing to advanced stages even in the absence of serious symptoms, thus leading to delayed diagnoses and dismal prognoses.

\section{Conclusion}

This study shows that oesophageal squamous cell carcinoma is the predominant type of oesophageal cancer while adenocarcinoma is the predominant gastric cancer in our environment. Tobacco, alcohol and spices are the main risk factors identified to be associated with the development of both oesophageal and gastric tumors. In view of the fact that upper GI tumors can rapidly progress to advanced stages in the absence of serious symptoms, gastroduodenoscopy is advocated in patients with signs and symptoms of dyspepsia to avoid delayed diagnosis and improve the disease prognosis.

\section{References}

[1] Mahmoud, K., Musaad, A., Mohamed, A.A. and Alawad, A. (2014) Pattern of Primary Gastrointestinal Tract Cancer in a Tertiary Central Hospital in Sudan: A Prospective Study. Medicine Journal, 1, 34-37. 
[2] Durrani, A.A., Yaqoob, N., Abbasi, S., Siddiq, M. and Moin, S. (2009) Pattern of upper Gastrointestinal Malignancies in Northern Punjab. Pakistan Journal of Medical Sciences, 25, 302-307.

[3] Atherfold, P.A. and Jankowski, J.A. (2006) Molecular Biology of Barrett’s Cancer. Best Practice \& Research Clinical Gastroenterology, 20, 813-827. http://dx.doi.org/10.1016/j.bpg.2006.04.003

[4] Bane, A., Ashenafi, S. and Kassa, E. (2009) Pattern of Upper Gastrointestinal Tumors at Tikur Anbessa Teaching Hospital in Addis Ababa, Ethiopia: A Ten-Year Review. Ethiopian Medical Journal, 47, 33-38.

[5] Whelan, S.L., Parkin, D.M. and Masuyer, E (1993) Trends in Cancer Incidence and Mortality. IARC Scientific Publications, Lyon, IARC Scientific Publications No. 102.

[6] Parkin, D.M., Bray, F.I. and Devesa, S.S. (2001) Cancer Burden in the Year 2000. The Global Picture. European Journal of Cancer, 37, S4-S66. http://dx.doi.org/10.1016/S0959-8049(01)00267-2

[7] La Gamma, N. and Nandakumar, G. (2013) The Management of Gastrointestinal Tract Malignancies. Hospital Practice, 41, 7-15. http://dx.doi.org/10.3810/hp.2013.04.1021

[8] Edington, G.M. and Maclean, C.M.U. (1965) A Cancer Rate Survey in Ibadan, Western Nigeria, 1960-63. British Journal of Cancer, 19, 471-481. http://dx.doi.org/10.1038/bjc.1965.55

[9] Mulligan, T.O. (1970) The Pattern of Malignant Disease in Ilesha, Western Nigeria. British Journal of Cancer, 25, 110. http://dx.doi.org/10.1038/bjc.1970.1

[10] Williams, A.O. and Edington, G.M. (1967) Malignant Disease of the Colon, Rectum and Anal Canal in Ibadan, Western Nigeria. Diseases of the Colon \& Rectum, 10, 301-308. http://dx.doi.org/10.1007/BF02617144

[11] Atoba, M.A., Olubuyide, I.O. and Aghadiuno, P.O. (1989) Gastrointestinal Malignancies in a Young Tropical African Population. Tropical Doctor, 19, 135-136.

[12] Obafunwa, J.O. (1990) Pattern of Alimentary Tract Tumours in Plateau Sate: A Middle Belt Area of Nigeria. The American Journal of Tropical Medicine and Hygiene, 93, 351-354.

[13] Oluwasola, A.O. and Ogunbiyi, J.O. (2003) Gastric Cancer: Aetiological, Clinicopathological and Management Patterns in Nigeria. Nigerian Medical Journal, 12, 177-186.

[14] Abdulkareem, F.B, Faduyile, F.A, Daramola, A.O, Rotimi, O., Banjo, A.A.F., Elesha, S.O., Anunobi, C.C.O., Akinde, O.R. and Abudu, E.K. (2009) Malignant Gastrointestinal Tumours in South Western Nigeria: A Histopathologic Analysis of 713 Cases. WAJM, 28, 173-176.

[15] Walker, A.R., Adam, F., Walker, J. and Walker, B.F. (2002) Cancer of the Oesophagus in Africans in Sub-Saharan Africa: Any Hopes for Its Control? European Journal of Cancer Prevention, 11, 413-418. http://dx.doi.org/10.1097/00008469-200210000-00002

[16] Ohanaka, C.E. and Ofoegbu, R.O. (2002) The Pattern of Surgical Cancers in Nigeria: The Benin Experience. Tropical Doctor, 32, 38-39.

[17] Ahmed, A.A. (2000) The Surgical Management and Outcome of Oesophageal Cancer in Addis Ababa. Ethiopian Medical Journal, 38, 147-152.

[18] Polednak, A.P. (2003) Trends in Survival for Both Histologic Types of Esophageal Cancer in US Surveillance, Epidemiology and End Results Areas. International Journal of Cancer, 105, 98-100. http://dx.doi.org/10.1002/ijc.11029

[19] Walther, C., Zilling, T., Perfekt, R. and Moller, T. (2001) Increasing Prevalence of Adenocarcinoma of the Oesophagus and Gastro-Oesophageal Junction: A Study of the Swedish Population between 1970 and 1997. European Journal of Surgery, 167, 748-757. http://dx.doi.org/10.1080/11024150152707725

[20] Powell J, McConkey CC, Gillison EW, Spychal RT (2002) Continuing Rising Trend in Oesophageal Adenocarcinoma. International Journal of Cancer, 102, 422-427. http://dx.doi.org/10.1002/ijc.10721

[21] Islami, F., Kamangar, F., Aghcheli, K., Fahimi, S., Semnani, S., Taghavi, N., et al. (2004) Epidemiologic Features of Upper Gastrointestinal Tract Cancers in Northeastern Iran. British Journal of Cancer, 90, 1402-1406. http://dx.doi.org/10.1038/sj.bjc.6601737

[22] Sambasivaiah, K., Ibrarullah, M., Reddy, M.K., Reddy, P.V. and Wagholikar, J.S. (2004) Clinical Profile of Carcinoma Stomach at a Tertiary Care Hospital in South India. Tropical Gastroenterology, 25, 21-26.

[23] Phukan, R.K., Narain, Z.E., Hazarika, N.C. and Mahanta, J. (2006) Dietary Habits and Stomach Cancer in Mizoram. Indian Journal of Gastroenterology, 41, 418-424. http://dx.doi.org/10.1007/s00535-006-1761-x 